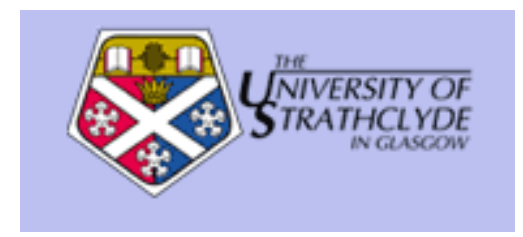

Barry, Monica (2010) Social capital in the lives of young carers.

http://strathprints.strath.ac.uk/20231/

Strathprints is designed to allow users to access the research output of the University of Strathclyde. Copyright (C) and Moral Rights for the papers on this site are retained by the individual authors and/or other copyright owners. You may not engage in further distribution of the material for any profitmaking activities or any commercial gain. You may freely distribute both the url (http://strathprints.strath.ac.uk) and the content of this paper for research or study, educational, or not-for-profit purposes without prior permission or charge. You may freely distribute the url (http://strathprints.strath.ac.uk) of the Strathprints website.

Any correspondence concerning this service should be sent to The Strathprints Administrator: eprints@cis.strath.ac.uk 


\section{CHAPTER X : SOCIAL CAPITAL IN THE LIVES OF YOUNG CARERS}

\section{Monica Barry}

\section{INTRODUCTION}

Approximately three million children live in families affected by a chronic mental or physical health problem or disability. However, under six per cent are officially recognised as young carers (Dearden \& Becker, 2005). Young carers are often isolated, their caring roles leaving few opportunities for social and leisure activities, employment or friendship networks. The caring role can bring social isolation and mental health problems for young people (Dearden and Becker, 2000). Some rarely leave their homes except to go to school, and often young carers' school work is disrupted by their caring duties, leaving them disadvantaged in terms of educational outcomes. Some young carers are also vulnerable to being admitted to care if their family member is hospitalised or dies. The Department of Health estimated that in 2000, the third most common reason for being admitted to care was parental ill health (Dearden \& Becker, 2005).

Becker (2000: 378) defines young carers as:

Children and young persons under 18 who provide or intend to provide care, assistance or support to another family member. They carry out, often on a regular basis, significant or substantial caring tasks and assume a level of responsibility which would usually be associated with an adult.

With many families being in receipt of benefits and unable to work because of the illness or disability, and with the majority of young carers living in single parent families, they are more likely to be living in poverty, thus exacerbating their access to social and other forms of capital. Young carers are by definition living with difficult home circumstances. Their parents or siblings may be suffering from long term ill health, disabilities, drug or alcohol dependency or mental health problems. Low confidence and low self esteem are also common amongst this group, making the formation of relationships outside the family even more difficult.

Community care policies often assume that care for ill or disabled relatives can be provided by other family members, irrespective of age, and friends and neighbours; in other words, relying on social capital within the local community. Whilst there is a wider debate about the role of the state in providing such a service, the issue for young carers in particular is that they have limited access to social capital by dint of their age and status. They may take on an unprecedented amount of responsibility in childhood for the welfare of vulnerable adults within the family, which in itself may give them a degree of social capital within the family. However, this is usually at the expense of access to social capital within schools and the wider community. Two young carers themselves explain their role as follows:

We do jobs such as shopping and make decisions, like about what we eat and when we eat. We cook, clean, face the people in housing and council departments when our parents can't or won't do it. We face teachers and our friends and deal with keeping our home lives secret... Teachers shout if you 
are late, but you cannot stand in the middle of class saying you have helped your mentally ill dad or mum because you'll be mocked and bullied. I felt isolated from my friends as I hardly ever saw them at school, and never saw them out of school as I was far too tired, busy or had no money due to my parents being on benefits or money being spent on alcohol (Henry and Morton, 2005: 267-268).

In 2007, a pilot study of young carers' perceptions of their families and wider networks was undertaken with the aim of developing a greater understanding of how those working with young carers can better identify their social and support needs and preferences (Barry \& Allan, 2008). A particular emphasis was on social capital, both in school and in the community, and how to inform the knowledge base, theoretical and empirical, relating to social capital more generally for young people. Likewise, it was hoped that this research would better inform teachers and social care workers about how to promote social capital amongst young carers who may not feel able to make full use of the educational and social supports available within their local communities because of their caring commitments.

The research thus sought to answer the following research questions:

- to what extent do different forms of social capital impact on current and future opportunities for young carers;

- to what extent can various agencies and significant others (including teachers, young carers' projects and friends) help young carers to identify and build on the types of social capital they identify as important to them.

\section{METHODS}

Four young carers projects in Central Scotland provided a sample of twenty young carers, 10 male and 10 female, in the age range $12-23$. Although the majority of young carers tend to be female (Dearden \& Becker, 2005), it was seen as important to sample an equal proportion of young male carers, who may have less access than their female counterparts to social capital in childhood and youth (Barry, 2006). One-toone semi-structured interviews were conducted with the 20 young carers who gave their prior consent to participate in the research. Given the sensitivity of the research questions, one-to-one interviews were deemed more appropriate than focus group discussions, especially in a pilot project of this size, and was felt to elicit more exploratory data than, for example, self-administered questionnaires. The initial proposal for the study was developed by Michael Gallagher and the fieldwork undertaken by the writer and Maria Paredes during the period June - December, 2007.

The concept of social capital is inherently difficult to define in academic circles, let alone amongst children and young people. However, the researchers attempted to explore with young carers issues relating to friendships, supportive relationships, family versus wider networks and the 'dark side' of social capital (Field, 2003) as well as its benefits. The fieldwork involved interviewing young carers about various aspects of social capital, including: their caring roles and their views and experiences of aspects relating to social capital, such as trust, networks, responsibilities and supports, not only within their families but also within the school, within social care organisations, amongst their peers and within the wider community. The discussions, 
through one-to-one interviews, also covered young carers' past achievements, their future needs, aspirations, and expectations and the impact of their caring role on their actual and perceived need for such networks and support.

The types of illnesses or disabilities that required these young people's care included mental or physical disabilities, mental health problems, alcoholism and physical illnesses. The types of caring role that they took on included looking after siblings (whether or not these siblings were the family members for whom they cared), shopping, doing housework, cooking, attending to medication or physical care tasks and offering emotional support. Sixteen respondents suggested that they cared for their mothers, fathers or both parents whilst the remaining 4 cared for one or more of their siblings. Often these young people cared for two or more family members with illnesses, disabilities or other problems, and on occasion, their caring role often extended beyond the family home to friends, other peers and other relatives living elsewhere. This resulted in them often taking on multiple roles and tasks of a practical, medical or emotional nature with different individuals in different settings.

\section{THE CONCEPT OF SOCIAL CAPITAL}

The term 'social capital' was coined by a schools' reformer, Hanifan, in 1916 to denote the 'good will, fellowship, sympathy and social intercourse among the individuals and families who make up a social unit' (Putnam, 2000: 19). Only in the latter part of the $20^{\text {th }}$ century did it again come to the fore as an explanatory tool for communitarianism and social networks. To Coleman (1988), social capital combines rational action with social structure, including obligations, trust, expectations, norms and information-sharing, but only where beneficial: 'A given form of social capital that is valuable in facilitating certain actions may be useless or even harmful for others' (Coleman, 1988: 98). He thus implies that social capital is rational and utilitarian, and if proving more damaging than beneficial, then that particular source of social capital will cease to be utilised.

Following on from Coleman's communitarian interpretation of social capital, Putnam identified four strands of social capital as follows: a) civic community networks; b) a 'sense of belonging' to a civic community; c) norms of reciprocity and trust; and d) positive attitudes towards, and engagement in, voluntary, state and personal networks (Morrow, 1999). More recently, Putnam has identified two sub-categories of social capital: bonding social capital (exclusive and inward-looking group identities) and bridging social capital (inclusive and outward-looking group identities) (Putnam, 2000: 23) which he describes thus: 'Bonding social capital constitutes a kind of sociological superglue, whereas bridging social capital provides a sociological WD40 '.

Like Coleman, Putnam acknowledges the adversarial as well as the consensual impact of social capital. However, Putnam's concept of social capital is seen as inappropriate to the experiences of young people, not least because young people tend to be excluded from civic participation and develop their own individualised social networks (Morrow, 2001; Raffo \& Reeves, 2000). Morrow (2001: 55) also argues that Putnam's concept is 'a woolly, catch-all category' and ignores the historical and economic context, is gender-blind, is culturally specific to the USA only and tends to ignore individual agency in generating one's own social capital. Morrow (2001: 2105) 
argues that because young people from more disadvantaged communities tend to draw on bonding rather than bridging social capital within such communities, they can only 'get by' rather than 'get on', but that these individualised social networks are more important to young people than communities per se.

Webster et al. (2004: 30) comment on the adversarial nature of some sources of bonding social capital notably in relation to young people, which can 'exclude, marginalise, constrain and entrap' them, and MacDonald and Marsh (2005), like Morrow, suggest there is a 'paradox of networks' (ibid: 203), where poorer areas can lack bridging social capital but are nevertheless a major source of support and legitimate opportunities for young people.

The French sociologist, Pierre Bourdieu, attempts to bridge the gap in social theory between agency and structure, without losing the 'major contribution of the structuralist legacy to social science' (May, 1996: 125). Bourdieu (1990) suggests that individual and collective constructions of the social world are not developed in a vacuum but are reproduced by, and themselves reproduce, social structures and are thus subjected to structural constraints. There is a constant interplay between structural constraints and individual choice, and the importance of time, space, agency and the individual's capacity to change are all implicated in the construction and reconstruction of the social world (Bourdieu, 1990). He stresses personal networks and power relationships and focuses as much on agency and sociability as on structure and institutionalization. He argues that individuals accrue capital - social, cultural, economic and symbolic - through their social practice, starting with social capital, which he describes as:

the aggregate of the actual or potential resources which are linked to possession of a durable network of more or less institutionalized relationships of mutual acquaintance and recognition - or in other words, to membership in a group - which provides each of its members with the backing of the collectively-owned capital, a "credential" which entitles them to credit. Bourdieu (1997: 51)

In other words, social capital is valued relations with significant others and is generated through relationships which in turn bring resources from networks and group membership. To Bourdieu, social capital includes not only social networks but also 'sociability' - 'a continuous series of exchanges in which recognition is endlessly affirmed' (1986: 250). Bourdieu's focus on 'sociability' in respect of social capital seems to suggest that social capital theory is less relevant to young people and their families in that Bourdieu sees familial ties as producing more cultural than social capital and that social capital comes more from wider social relationships. Equally, Bourdieu's approach to social capital is somewhat utilitarian in nature and does not allow for reciprocity and 'giving back' to others of social capital that one has already accrued from others.

Young carers in particular may have a natural proclivity to give more than they receive but equally value reciprocal relationships with others, notably their friends, through trust, loyalty, keeping secrets and being mutually supportive. However, social capital can be constrained by the strong bonds developed within families marred by illness, marginalisation and death, by the negative perceptions that many young carers 
have of 'supportive' professionals such as teachers or social workers, and by their resultant recourse to self-sufficiency and responsibility taking. Young carers represented in this study may take on more family responsibilities than most young people in childhood and may have to cope with often adverse reactions from peers, professionals and the public not only as a result of their family circumstances but also because of their status as 'young people'. Nevertheless, like many young people, they demonstrate a high degree of resilience and build coping mechanisms to protect themselves, their families and their close friendships during this period of transition. Transitions for them may be familial (from two parent- to one-parent families, from diagnosed illness/disability to stability, recovery or even death); educational (from primary to secondary school); developmental (from adults caring for them to them caring for adults); and/or social (from familial dependence to wider friendship networks). These transitions can be fragmented and disrupted, and yet they are rarely supported by the external world but negotiated primarily by the young people themselves, bolstered by the social capital (support and encouragement), however tenuous, that they accrue through close friendships, family cohesiveness and young carers projects in particular.

\section{THE SIGNIFICANCE OF OTHERS FOR YOUNG CARERS}

Young people were asked at interview about the people who were significant to them - whether this be positively or negatively - in their daily lives. These people mainly comprised family members (both living and deceased) and peers, and the numbers of significant others identified ranged from 4 to 19 and all bar one included family members. These people included parents or step parents, grandparents, siblings, cousins, aunts and uncles, friends/peers, teachers and young carers project workers. However, the most commonly cited people were family and peers. Cree (2002) found that young carers tended to share their problems mostly with their mothers, friends and young carers project staff, and this range of significant people in their lives is explored further below.

\section{Family}

Eleven of the 20 respondents stated that their parents had separated or divorced, but that they still kept in touch with the other party living elsewhere. There tended to be a lot of movement between family members living in different locations - for example, where parents were separated or where grandparents or siblings lived elsewhere, albeit usually locally. Fifteen of the 20 respondents (10 young men and 5 young women) mentioned that they were particularly close to their mothers, including one who had died, and 9 (6 young men and 3 young women) suggested that they were particularly close to their fathers, again including one who had died, although 6 did not mention their fathers. Whilst one felt that he was close to his step-father, another a 12 year old young man - stated that his step-father treated his mother 'like a piece of rubbish... He's got no right talking to my mum like that' (12 year old male).

However onerous the caring task may seem to these young people and however worrying in terms of what the future might hold for that family, being a young carer was seen as a definite bonding mechanism between the young person and his/her family. None of the respondents seemed to resent the role that they had as a young carer, although it may at times cause arguments or tension within the household. 
Whilst five respondents were an only child, others spoke affectionately about their siblings, and whilst they may argue, they tended to confide in and support them, whether they lived with them or not. Grandmothers were also spoken of highly.

Three respondents mentioned having suffered bereavement within the last five years, resulting from the death of a close family member. It may well be that there were more young people who had experienced the death of a relative or friend, but those that mentioned it at interview suggested it had impacted greatly on them. One young man whose aunt had recently died described her as 'more of the woman figure in my life' (14 year old male) and one young woman's mother, for whom she had been caring prior to her death some years ago, was described as: 'my best friend, my sister, my mother, all in one... my mum was my life' ( 22 year old female). Two further respondents mentioned that a parent or other family member would, in the foreseeable future, die as a result of their illness, and one feared that her parents may again attempt suicide as a result of their ill health. Some respondents seemed torn between their caring role at home and their desire to keep in touch with other family members living elsewhere. In one case, where a young man's estranged father was seriously ill, he felt guilty about going to see his father when he should have been caring for his disabled mother.

\section{Peers}

The significance of peers in the transition to adulthood cannot be underestimated, with Coleman (1990) suggesting that friends take on a greater significance in adolescence than the family, but that many young people worry about upsetting or endangering those often tenuous but positive friendship ties. Nevertheless, friends featured large in the lives and loyalties of these young people and they tended to choose their friends because of common interests, common experiences (such as being a young carer) or feeling that they could trust and confide in certain of their peers rather than others. 'Having a laugh' was a significant factor in the common bond between friends, and although some felt that moving away from an area or a school might lessen the bond between friends, others felt that the friendship was strong enough to cope with distance. One young man felt that one friendship had remained strong even though they lived further away from each other, and that leaving school would not create a barrier to continuing to meet: 'we've already bridged that gap'.

The constraints on young people's social and geographical mobility has been highlighted by a recent study of territoriality in the UK (Kintrea et al, 2008), where it was found that territoriality can lead to isolation, fear and violence for those innocently caught up in such practices, whilst for the perpetrators, territoriality created a 'darker side' of social capital through group affiliations, solidarity and identity. One young person suggested that she could not visit a certain friend because her parents felt the neighbourhood in which that friend lived was unsafe. Several other respondents mentioned peers who they either disliked or wanted to avoid, because of a fear of violence, harassment and bullying.

The vast majority of respondents spoke highly of their friends as having a positive impact on them. Many said that friends helped them to take their mind off the caring role or the family situation and they were often torn between their home commitments 
and their desire to be out with friends. Often they needed to juggle their responsibilities at home with the time available to see friends and this could result in emotional tension and feelings of guilt. This often meant that going to school provided an ideal opportunity to meet friends during the day.

Although some respondents mentioned having friends in secondary school who had also been close to them in primary school, most gave the impression that affiliations changed over time or that the move to secondary school precluded their continuing relationships with former primary school friends. Although many were close to their families, they never seemed to tire of being with friends, as one respondent commented: 'you'd think if you spent that much time with someone, you'd hate them' (15 year old male).

Whilst their friends were often supportive of their role as a young carer, knew the family situation or were confided in about their friend's caring role, some respondents felt uneasy about inviting friends into the family home because of embarrassment or wishing to protect the feelings of other family members. Two young carers whose mothers suffered from alcoholism commented about their friends: 'I wouldn't want [them] to see my mum' (16 year old female), and '[they] never came up when she was ill... I'm quite happy to invite them up now [that she's better]' (12 year old male).

There seemed to be no difference between male and female respondents about their attitude to friends, although the young women tended more than the young men to mention the emotional bond of friends, whereas the young men were more likely to cite leisure pursuits with friends as being an important bonding mechanism.

\section{Teachers}

School was not only seen as a place of education but as serving a primary function as a meeting place for friends. However, whether the school setting is of greater importance in this function for young carers (who may not be able to leave the family home during evenings and weekends because of their caring role) or whether school serves as a social forum for all young people is beyond the scope of this research. However, school was also seen (perhaps fortuitously!) as a centre of education and learning, as one young man surmised: 'If it wasn't for school, we wouldn't have an education' (14 year old male). However, overall the comments about schooling and teachers per se were more negative than positive, with 13 respondents citing negative facets of school, 8 citing factors and 5 expressing mixed views. The main criticisms were levelled at the attitude of teachers rather than the quality of education. For example, several found it difficult to justify the aggressive or authoritarian approach of some teachers, as the following quotation illustrates:

They think they can do whatever they want. They think they can shout at you and give you more work, but I just can't take it... There was one teacher that was really getting on my nerves and I just shouted at her. But she chucked me out of the class, so I never got a chance to shout at her properly (16 year old female). 
Some young people felt that teachers were not supportive enough of pupils who were behind or struggling with the workload and a few respondents suggested that teachers could do more to encourage pupils to enjoy being at school:

I never hated anything more in my life... I hated it, it was horrible... It's just, if they give you the right help and they make it interesting, then you'll pass and you'll do well, but if you're bored with it and they just shout at you or whatever, you're just going to be like, whatever (15 year old female).

Of the young people who enjoyed school, most suggested that it was certain teachers or the ambience of a particular school that helped them. One young woman who resented moving to a third high school by the time she was in fourth year (because of family ill health) was now feeling more positive about school: 'I actually do enjoy school, it's quite scary!' (16 year old female) and she had decided to stay on until sixth year. This change of attitude came about partly because of the friends she had made at her most recent school but also because she felt her school work was improving following the further help she had requested from her new teachers.

School bullying is an increasing concern for pupils, teachers and policy makers alike and whilst 7 respondents said that they had been bullied themselves in primary or secondary school, most had indirect experience of it and could comment on the issues involved. Bullying was said to result from various factors: being overweight, being a carer or having a disabled sibling, coming from a minority ethnic background, suffering from ADHD or just being outwith the friendship circle of the bullies. One young woman suggested that girls rather than boys were more prone to bully others, because 'girls hold grudges'. Six young people said that teachers did not respond constructively to reports of bullying and told those experiencing such harassment to either fight back or to take evasive action. Whilst one respondent asked to be moved to another school because of bullying, another did not want to move because of having established friends in the current school. One young woman who had been suicidal as a result of such bullying felt that the school's response was 'diabolical', noting that violence had to be 'seen' before the school would take action against bullies.

The role of school for young carers can be an ambivalent one: partly it can be a 'safe haven', away from the worries of the caring role, but also some respondents suggested that they wanted to keep school separate from that caring role, almost so as not to 'contaminate' that safe haven. One young man explained it as: 'my personal life is not in school. In school is school' (12 year old male). Several respondents also suggested that they purposefully did not want the school to know they were a young carer either because they may get preferential treatment which they did not want, or because they may be treated more harshly, and the following quotations illustrate this dichotomy:

My guidance teacher, he knows a lot about my situation which other teachers wouldn't, so when I've no time to do homework or whatever, he'd be able to sympathise with me and make some sort of agreement with me, whereas other teachers just say 'oh, no, you're just at it now' sort of thing (14 year old male).

I'd rather them not know [I'm a carer]... If I was late and there was a reason I was late, then I can't just sit there and go 'it was because of this', because 
they're not going to believe me... [or] they might treat me different, and I don't want them to... they might give sympathy and I don't want it. I just want to be the same as everyone else (16 year old female).

Some respondents singled out specific teachers who knew their situation and were supportive, understanding and would give an extension for homework if there was a change in the circumstances at home that prevented the young person from doing school work. Nevertheless, some teachers likewise were either not adept at understanding, or perhaps were not given the discretion to accommodate the needs of young carers, as the following quotations suggest:

There's a wee bit more understanding [at school] about young carers but there is still room for improvement. School was brilliant when my mum died. They understood everything... 'oh, your mum's died, oh we can do this, we can do that, and we can do the next thing for you'. Eh? What happened before my mum died?... I think it's more sort of black and white when there's a death (22 year old female).

With teachers, you're always conscious if you say something, it'll get blown out of proportion or they'll go and phone your mum or something... teachers try too hard to relate to pupils instead of relating to pupils' problems... they're trying to be like us rather than understand us (15 year old female).

This latter quotation highlights the dilemma perhaps for teachers as being 'mentors' and yet also 'agents of the state' in terms of child protection, education and discipline. These young carers were probably more wary of confiding in teachers about their problems, because they felt that teachers could not be trusted in the same way as a friend could, or alternatively that their request for help might be taken out of their hands and dealt with by adults without their prior consultation or consent: being 'listened to' (in a consensus building way) is not something that young people generally feel happens in their dealings with adults (see, for example, Franklin, 2002).

\section{Professionals}

Few young people mentioned other professionals in their lives or those of their families, and yet it could not be ascertained at interview whether this was because they themselves were unaware of other agencies' involvement with the person(s) being cared for or whether other agencies were not involved because the family was seemingly coping on its own. The types of professional support mentioned by respondents were either for the person being cared for specifically - e.g., a befriending service, medical or health professionals or social work support, or for the young carer specifically - e.g., counselling or learning support at school, a young carers project, a psychologist, social work support or a job skills agency. The supports offered to these families included respite care, help with shopping, counselling and health advice, but there was a suggestion that such help was minimal, either because services had been withdrawn because of funding or health and safety (of home care workers, for example), or because the agencies did not specialise in or necessarily understand certain diagnoses or needs.

\section{Neighbours}


The community in which one lives is often regarded as a crucial source of social capital, and yet increasingly communities are being eroded by factors such as social mobility, employment constraints, housing policies and greater use of the internet. Equally, within the context of community care, neighbours are often regarded as a crucial source of social and human capital, serving as a bridge between those who may be housebound and the wider community (through shopping on their behalf, holding a spare set of house keys or offering practical support in the home when requested). Nevertheless, neighbours were often not mentioned by these young people as featuring significantly in their families' lives, and where they were mentioned, they did not seem to be viewed in a particularly positive light, either because they knew too much or enquired too much about the family. However, equally, one young man mentioned that 'neighbours come and go' (23 year old male), not least when his own family had lived in the same house since his early childhood.

\section{Young carers projects}

Because the sample had been accessed through young carers projects, and all respondents were active members of such projects, it is understandable that they mentioned gaining a great deal of support and comfort from that type of project involvement. This section therefore focuses on the views and experiences of these young people, notably about their involvement in the five young carers projects in Scotland from which the total sample was drawn and about their perceptions of the caring role.

One young person described caring as 'normally just a reaction... an instinct' (15 year old male) and another said: 'It doesn't really feel like a chore, because rather than feeling I have to do it, I feel I want to do it' (16 year old male). Several suggested that they had spent most of their young lives caring for a member of the family, with one saying that she had cared for her mother, and been at a young carers project, since the age of 4 , outliving several of the project staff. These young people had taken on a range of responsibilities from an early age, and felt more protective of their families and more mature within themselves as a result, as one young man commented: 'I'm 20 but I'm only 12 '.

Several respondents mentioned not only the tensions arising from taking on a caring role within often tightly knit family circles, but also the tensions arising from being an adolescent growing up in a family affected by illness or disability. Young carers projects were seen as helping these young people for both these reasons, in offering support of a practical or emotional kind for young people dealing with other family members' issues as well as their own. The projects that these young people attended, albeit often only once a fortnight or once a month depending on project funding and staffing, were spoken highly of by all respondents. The reasons why they viewed these projects so positively were three-fold: a) because of the sociability aspect of attending; b) because of feelings of 'release' from the home situation; and c) because of the emotional support they received. These three factors are explored in greater detail below.

\section{Sociability}


Undertaking activities and going on outings with friends through the project was seen as one of the primary attractions of attendance at a young carers project. Outings and activities are a common bond and vehicle to relieve boredom for young people with few alternative leisure opportunities, but perhaps more so for young carers who are depended on within the home on a regular basis:

I like it. It helps me get out and that... my mum worries when I go out... she knows when I come here, I'm safe and I'm with friends and that, so I like it (14 year old female).

These young carers often described their young carers project as 'a laugh' and somewhere where they could meet new people as well as existing friends. They also spoke highly of the staff, who were 'there for you' when needed.

\section{Feelings of release}

Not only was a young carers project somewhere where you could meet socially, enjoy new networks and activities and be offered emotional support, but it was also somewhere divorced from the family situation and the caring role and enabled these young people to get out of the house and into new and supportive surroundings, if only once a month. Many young people spoke of the 'respite' element of attendance, as the following quotations illustrate:

You come here to forget about it all really. It's just in the back of your mind, but you know if you did have to talk to someone, they would be happy to talk about it... they know the situation I'm going through (16 year old female).

They always take us places and get us out of the road for a wee while, so it takes your mind off all the stuff at home (14 year old male).

There were mixed feelings amongst respondents about whether or not they wanted to use the project as a means of forgetting or confronting their caring role, with some saying they did not like to talk about caring at the project, but to use it as a form of release, whereas others suggested that talking about it to staff or other young people was in itself a form of release, as the following sub-section illustrates.

\section{Emotional support}

The emotional support offered by the project was seen as one of the most important aspect of attendance, through talking about problems/issues with both staff and other young people and through being able to empathise with people in similar situations to themselves, something they could not easily do with friends in different family settings:

[At the project] there are lots of people that are in the same situation as you. And friends at home, they don't understand that you have to go home and care for your mum and dad, because their mum and dad actually care for them. But here, many people are in the same situation so it's a lot easier to talk to people (16 year old female).

When I was younger, it was a lot harder to explain to people why I couldn't do things and why I couldn't go out, because I was embarrassed to explain my 
situation... you kind of felt like there was nobody out there in the same situation as you. But when I came to Young Carers I realised that I wasn't alone (15 year old female).

\section{PERCEPTIONS OF SELF}

The young people at interview were asked how they would describe themselves or how their friends might describe them. Seven respondents described themselves in terms of the skills they had - for example, being able to cook, sing, dance or play football. Others described themselves in terms of personality traits, being what could be summed up as 'self-sufficient' (4 respondents), confident (3 respondents) and nonviolent ( 2 respondents). Other personality traits, mentioned by one respondent each, were popular, friendly, a joker, shy and 'too passionate':

My mum said I'm too passionate. When Rangers got kicked out of the last 16 of the European Champions League, I think I was the only person in the place crying! (14 year old male).

It's quite hard for me, because I'm quite shy just now, but I'm more confident. It's just like in school situations... it's hard to meet people you've known from a different area. But if I'm out and about skating and stuff, it's dead easy and you can just go and talk to them, because they don't know your history and they can't judge you or anything... the fact that I was really, really shy (16 year old female).

Yet other respondents described themselves in relation to other people, namely that they could give good advice ( 7 respondents), that they were protective of others ( 3 respondents) and that they were trustworthy (2 respondents). Part of this advicegiving, protectiveness and trustworthiness came from their role as a carer, which may have become part of their persona, as one young woman explained:

I'm that used to caring that I care for everybody... probably if you had to take everybody away and just leave me, I would struggle cos' I couldn't care for somebody else. Caring for myself is just a basic instinct, whereas caring for someone else is something that I know I can do, if that makes sense... once you stop caring for them, you sort of need to find somebody else to care for (22 year old female).

Whether the caring role that these young people took on heightened their sense of responsibility for others is an hypothesis beyond the scope of this research, but nevertheless, all these young people felt a strong sense of responsibility for others. Nine said that they felt responsible for one or both parents (to protect them from harm), 8 for siblings (to offer a role model, activities, a feeling of being safe, or an education) and 6 for friends (to be there for them when needed).

When asked about what these young people would like to be doing in the future, the vast majority focused primarily on doing well at school, passing examinations and going to college or university. In terms of future professions, their main employment preferences were artistic/creative, caring or health-related professions, teaching sports or other subjects, joining the police, or other professions. Some mentioned wanting to 
have their own house but realised that they may still be needed to take on a caring role within the family. Indeed, the caring role was seen as the most likely 'obstacle' to their achieving their desired goals, because either they were the only carer or because of the seriousness of the illness/disability of their family member. The stronger the familial bond, the greater likelihood that this would restrict their opportunities in the future. Other obstacles to achieving their goals included having no money, current bullying at school resulting in them taking their own lives, their lack of confidence in their capabilities or capacities, and having no links with the world of employment.

\section{SOCIAL CAPITAL IN THE LIVES OF YOUNG CARERS}

Three theoretical implications have arisen from this research which highlight the prevalence and relevance of social capital in the lives of these young people. These are discussed below under the following headings:

- bonding and bridging social capital;

- the mobilization of resources; and

- the durability of social capital in transition.

\section{Bonding and bridging social capital}

Holland et al (2007) argue that staying within the 'comfort zone' of the caring role and the family network is often a positive, not a constraining, source of social capital for young people and that they positively choose to remain within that closed or narrow network. However, having said that, some of the young people that these authors interviewed suggested that bonding social capital was stifling and that they wanted more social mobility (getting on) than was available within the home environment (getting by). The young carers in this study often cited their caring role as a barrier to their future aspirations to make something of their lives, and equally tended to use school and friends as a welcome relief to the confines of their familial role.

These young carers seemed to move between two very strong, but totally separated, bonding groups: the family and the friendship group. But friends are also a 'bridge' away from the family - assuming a bridge can be an escape route from one bonding group as well as a link to another bonding group. In other words, friends offered them an alternative lifestyle and respite from the caring role, which arguably could be called 'bridging social capital'. However, because young carers may not want to bring friends home with them, and because parents may not interact with the activities of a young carers project - the emphasis of the project may be on the respite element, for young people to 'get away' from the parental home for a while - may both conspire to reduce the availability of bridging social capital for these young people. Family, friends and young carers projects are all kept separate (whether by design or choice), and social capital is kept contained within but not between each of these three social circles.

The 'closure' of the family, friendship and young carers project groupings might make bridging more difficult - as might these young carers' perception of themselves as being self-sufficient and able 'to cope'. They also had limited involvement with, or 
trust in, 'outsiders' such as teachers, doctors and social workers, exacerbated perhaps by their seeming desire to protect the family from outside interference or scrutiny.

\section{The mobilization of resources}

There is a distinction between a 'resource' (e.g., parents) and capital (the end product of that resource (e.g., trust or security). A resource only becomes capital if it is mobilized through a combination of structural and functional social resources (Lin, 2000). Bassani (2007) argues that social capital theory is limited and under-theorised in respect of youth studies, partly perhaps because close-knit families do not generate much transferrable social capital and young people cannot easily mobilise family resources to produce social capital themselves. Bassani suggests that only through the mobilisation of parental resources can young people create positive social capital. However, she tends to place the responsibility for mobilisation onto the young person, rather than suggesting that the parents themselves, or others, should mobilise their own resources for the benefit of young people, and she also stresses the importance of a healthy family relationship for mobilisation of parental resources to be effective. Nevertheless, it is arguable whether that relationship needs to be more reciprocal and mutually proactive to produce social capital. Because families tend to be 'closed' groups, they are often seen in the literature as curtailing or even preventing the building of wider social capital in 'outside' groups (Bassani, 2007).

Whilst in this study, young people seemed to offer to and receive from their peers certain resources which could result in social capital (trust and confidences, for example), they had mainly negative or dismissive views of 'outsiders', such as teachers or other professionals, suggesting that these adults either did not have the resources to mobilise on behalf of young carers or did not use those resources in the interests of young carers. Likewise, young people in the transition to adulthood may not wish to mobilise the resources of others as this may be seen to be a sign of weakness or dependence. Markers of adulthood for young people include accepting responsibility for themselves and others and becoming independent of adults. Sennett (2003) suggests that self-sufficiency gains one respect through not being seen to be a burden on others. However, he realises that self-sufficiency can go against the need to belong to a group through mutual ties of inter-dependence and sharing. In wanting to become adult and to gain respect, young carers may not fully grasp the importance or value of seeking help or acknowledging their limitations. They may therefore not identify with, or grasp, the significance of social capital in their own lives.

\section{The durability of social capital in transition}

Bourdieu has always maintained that capital has to be durable in order to be effective (Bourdieu, 1990; Bourdieu \& Wacquant, 1992). I would argue that durability is, almost by definition, absent in the transition to adulthood, where 'youth' is a temporary and liminal phase and young people's resources are constantly changing and uncertain. This uncertainty (or lack of durability) for young carers is also evident in their concern about the health and future of the person they are caring for, making their own futures tenuous as well, and bereavement can undermine any sense of permanence or sustainability that young carers may have had in the past. Likewise, friends tend to lack durability at that age and the transition from primary to secondary school does not help to sustain earlier-formed friendships. Holland et al (2007) imply 
that one needs existing friends in order to make new friends, and that young people need existing friends who move to the same schools as them: 'having a stable base of bonds enabled many to bridge out to new friendships' (ibid: 102).

\section{CONCLUSIONS}

As mentioned above, social capital is inherently difficult to conceptualise, let alone to operationalise. It was therefore extremely beneficial to be part of the Applied Educational Research Scheme's Schools and Social Capital network. This network met on a regular basis throughout the period that these case studies were researched, bringing together academics and practitioners with knowledge and expertise of the concept of social capital, and providing both enthusiasm and motivation to delve deeper into the meanings of social capital for different groups of young people.

Although this particular study was limited to a small number of respondents, the narratives of these young carers have nevertheless thrown increased light on the issues and challenges faced in understanding social capital in relation to minority or vulnerable groups, such as young people taking on high levels of responsibility as carers of family members. These young people's social and spatial networks were restricted not only because of their age and status as children and young people but also because of their additional roles as carers of other family members. The role of young carers can exacerbate already limited networks for young people and limited access to geographical, leisure and civic spaces which may be more accessible for adults. Their social and spatial networks were predominantly confined to the home and the school environment, restricted by structural constraints on their choice of where and when to meet friends and when to be with their families.

Taking Bourdieu's four concepts of social, economic, cultural and symbolic capital together, there seems to be a tension for young carers as a vulnerable group in accruing and sustaining all forms of capital, not just social capital. Their desire for cultural capital (through academic qualifications) and eventual economic capital (through viable employment) is in direct competition with their desire to maintain the social and symbolic capital accrued within the family through the bond established in the caring role and the loyalty that results from such responsibility taking. Likewise, the social and symbolic capital accrued within the friendship group is in direct competition with that of the family, and loyalties are stretched between these two social and spatial networks.

The status of children and young people generally in the transition to adulthood restricts their access to durable friendship networks, as a result of the transience of youth and rapid developmental change. Young people tend to experiment with both adult and peer relationships at this time in their lives, and perhaps more often than adults need the feedback from others to develop their own sense of self and social identity. The challenges for social capital theory are in extricating these individual narratives about social networks from the structural constraints that envelope them: their responsibilities as carers, their liminal status as young people in transition and the dichotomy for them of 'getting by' rather than 'getting on'.

Although not focusing on social capital, two studies of young carers in Scotland in recent years have uncovered the need for support for this group to enable them to 
make better choices and have greater access to opportunities as young adults. Cree (2002) interviewed 61 young carers in Scotland and found that the vast majority felt a need for greater support in their caring role as well as in their role as emerging adults. Likewise, Banks et al (2001) identified four key needs of young carers in Scotland: 1) information on medical conditions and services; 2) individual support and counselling; 3) practical help; and 4) social contacts/activities. These authors found that whilst the caring role could adversely affect young people's attendance and performance at school, there were few systems in place within Education Boards to tackle these issues.

The stigma associated with disability or mental illness, for example, is always prevalent in the minds not only of young carers but also often of their families and each seeks to protect the other from resultant discrimination and embarrassment. Banks et al (2001) noted that some young carers and their parents are reluctant to engage with formal services because of such stigma and intrusiveness and also because of fears about the response of services to their requests/needs.

\section{THE IMPLICATIONS FOR POLICY, PRACTICE AND RESEARCH}

- the relevant agencies - education boards, social work departments and health boards - need to work more closely with young carers and their families to ensure that their needs are met and that they are encouraged, with other professionals, to build durable, positive and transferrable social capital for young people in transition;

- young carers projects need to be given the resources and time to engage meaningfully, regularly and over longer periods with young carers, and to fulfil their wishes for greater support in practical, emotional and educational terms;

- young carers themselves need to have the opportunity within confidential spaces to voice their concerns about their caring role, their families' circumstances, their developmental needs and their futures.

The implications for research relate primarily to the current lack of understanding of the role of social capital within the general population, let alone in relation to young people. However, research also needs to find ways to operationalise the concept of social capital in respect of young people whose social and spatial networks are already limited by dint of the fact that they lack status, recognition and support in an otherwise adult-oriented society. Vulnerable or marginalised groups such as young carers have an even greater need for the recognition and support that social capital can offer, not least because the role they have assumed in the family is one which would, if undertaken by adults, be seen as a valuable and responsible role.

\section{REFERENCES}

Banks, P., Gallagher, E., Hill, M., and Riddell, S. (2002) Literature review of identification, needs assessment and service provision for young carers and their families, Edinburgh: Scottish Executive Central Research Unit.

Barry, M. (2006) Youth Offending in Transition: The search for social recognition, Abingdon: Routledge. 
Barry, M. and Allan, J. (2008) Young Carers and Social Capital, Stirling: Stirling University.

Bassani, C. (2007) 'Five Dimensions of Social Capital theory as they Pertain to Youth Studies', Journal of Youth Studies, Vol. 10, No. 1: 17-34.

Becker, S. (2000) 'Young carers' in M. Davies (ed.) The Blackwell Encyclopaedia of Social Work, Oxford: Blackwell.

Bourdieu, P. (1990) In Other Words: Essays Towards a Reflexive Sociology (trans. M. Adamson), Cambridge: Polity Press.

Bourdieu, P. (1997) 'The forms of capital', in A. H. Halsey, H. Lauder, P. Brown and A. Stuarts Wells (eds) Education: Culture, Economy, Society, Oxford: Oxford University Press.

Bourdieu, P. and Wacquant, L. (1992) An Invitation to Reflexive Sociology, Cambridge: Polity Press.

Coleman, J. (1990) Foundations of Social Theory, Cambridge MA: The BelknapPress of Harvard University Press.

Cree, V. (2002) Under Pressure: A study of mental health needs of young carers, Edinburgh: Edinburgh Young Carers Project.

Dearden, C. and Becker, S. (2005) 'Growing up caring: Young carers and vulnerability to social exclusion' in M. Barry (ed.) Youth Policy and Social Inclusion: Critical debates with young people, Abingdon: Routledge.

Field, J. (2003) Social Capital, London: Routledge.

Franklin, B. (2002) (Ed.) The New Handbook of Children's Rights: Comparative policy and practice, London: Routledge.

Fukuyama, F. (1999) Social Capital and Civil Society, Paper presented at the IMF Conference on Second Generation Reforms, Washington: International Monetory Fund.

Henry, J. and Morton, B. (2005) 'Postscript on young carers' in M. Barry (Ed.) Youth Policy and Social Inclusion: Critical debates with young people, Abingdon: Routledge.

Holland, J., Reynolds, T. and Weller, S. (2007) 'Transitions, Networks and Communities: The significance of social capital in the lives of children and young people', Journal of Youth Studies, Vol. 10, No. 1: 97-116.

Kintrea, K., Bannister, J., Pickering, J., Reid, M. and Suzuki, N. (2008) Young people and territoriality in British cities, York: Joseph Rowntree Foundation. 
Morrow, V. (2001) 'Young people's explanations and experiences of social exclusion: retrieving Bourdieu's concept of social capital', International Journal of Sociology and Social Policy, Vol. 21, No. 4/5/6: 37-63.

Putnam, R.D. (2000) Bowling Alone: The collapse and revival of American community, New York: Simon and Schuster.

Raffo, C. and Reeves, M. (2000) 'Youth transitions and social exclusion: Developments in social capital theory', Journal of Youth Studies, Vol. 3, No. 2: 14766.

Webster, C., Simpson, D., MacDonald, R., Abbas, A., Cieslik, M., Shildrick, T. and Simpson, M. (2004) Poor Transitions: Social Exclusion and Young Adults, Bristol: Policy Press. 